\title{
Case report-ovarian torsion in a child: a painful twist in the tale
}

\author{
Ankur Gupta ${ }^{1}$, Prijo Philip ${ }^{2}$ \\ ${ }^{1}$ Dr. Ankur Gupta, Post Graduate Resident in Department of Pediatrics, ${ }^{2}$ Dr. Prijo Philip, Senior Resident in Department \\ of Pediatrics, Both authors are affiliated to K.S. Hegde Medical Academy, Nitte University, Mangalore, Karnataka, India.
}

Address for Correspondence: Dr. Ankur Gupta, Email: drankurgupta1987@gmail.com, Department of Paediatrics K.S.Hedge Medical Academy, Mangalore, Karnataka,575018 India.

\begin{abstract}
Ovarian torsion in children is a rare cause of acute abdominal pain and is a true surgical emergency. The clinical presentation closely resembles other pathologies such as urinary tract infections, gastroenteritis and more common surgical emergencies such as appendicitis. We present a case of previously healthy 6 year old female child who presented with abdominal pain, intermittent fever and vomiting. Ultrasonography of the abdomen and pelvis revealed features suggestive of ovarian torsion for which Subacute Laparoscopic Oophorectomy was performed. The authors would like to sensitize readers to the possibility of ovarian torsion in the paediatric populace and reiterate that timely diagnosis and management can prevent catastrophic sequelae.
\end{abstract}

Keywords: Abdominal emergency, Children, Ovarian Torsion, Ultrasonography.

\section{Introduction}

Ovarian torsion has been postulated to be an unusual cause of acute abdominal pain in children. Among the adult populace, it has been estimated to account for $3 \%$ of all cases of acute abdominal pain. Seventy one percent of these cases are seen in women beyond the second decade of life. It must be stressed that ovarian torsion is an emergency that warrants early suspicion, diagnosis and timely surgical exploration and de-torsion to avoid the calamitous consequences that further adnexal damage can cause. Due to its proclivity to mimic other acute surgical emergencies, very often a perioperative diagnosis becomes challenging, especially for primary care physicians [1]. Knowledge of the fact that ovarian torsion in the pediatric population is a possibility as well as its presentation can go a long way in preventing catastrophic sequelae.

\section{Case Report}

A previously healthy 6 year old girl presented to the Paediatric Emergency Department with 4 day history of diffuse lower quadrant pain, intermittent fever, and 3-4 episodes of vomiting. She was evaluated by a clinician a day before and was diagnosed with acute gastroenteritis after physical examination and negative

Manuscript received: $14^{\text {th }}$ August 2016

Reviewed: $26^{\text {th }}$ August 2016

Author Corrected; $10^{\text {th }}$ September 2016

Accepted for Publication: $23^{\text {rd }}$ September 2016 urinalysis. However, her symptoms persisted and in view of severe abdominal pain, she was admitted for further evaluation. Upon admission, the child appeared ill and uncomfortable. She had complaints of constant pain that was not relieved with analgesics. Her review of symptoms was positive for fever, 3-4 episodes of vomiting, and abdominal pain.

On examination, the patient's vitals were: oral temperature was $37.5^{\circ} \mathrm{C}$, heart rate of 90 , blood pressure of 104/70, and respiratory rate of 20 , and oxygen saturation was $100 \%$ on room air. The patient's abdomen was mildly distended and tenderness was present in the periumbilical, pelvic, and suprapubic areas. She had some involuntary guarding but no rebound tenderness or hepatosplenomegaly, no classic signs for appendicitis, as Rovsing's and Psoas signs were also absent. The remaining findings were normal including heart tones, lung sounds, capillary refill, and skin turgor. Urine analysis was normal.

Total counts were elevated at $17000 / \mathrm{mm} 3$ but other investi-gations were within normal limits. USG of the abdomen and pelvis revealed bulky left ovary seen in the midline posterior to the uterus with no obvious vascularity, suggestive of Ovarian Torsion. [Figure 1] Subacute Laparoscopic Oophorectomy was done in 
view of fully gangrenous left ovary. Right ovary appeared normal. The child was discharged on postoperative day 4 without further complications.
Follow-up ultrasound performed one month later was found to be normal.

\section{Discussion}

Ovarian torsion is a significant surgical emergency, and has been known to account for approximately $2.7 \%$ of all cases of acute abdominal pain in the pediatric populace [2]. Obstruction of venous outflow, infarction and necrosis, peritonitis and loss of adnexa results from rotation of the ovary along its vasculature, during normal mobility of the fallopian tube. This is particularly dangerous in young children due to the propensity for non-recognition, courtesy the rarity and the non-specificity of presentation [1] that can mimic conditions such as appendicitis, urinary tract infection, renal colic and gastroenteritis [3].

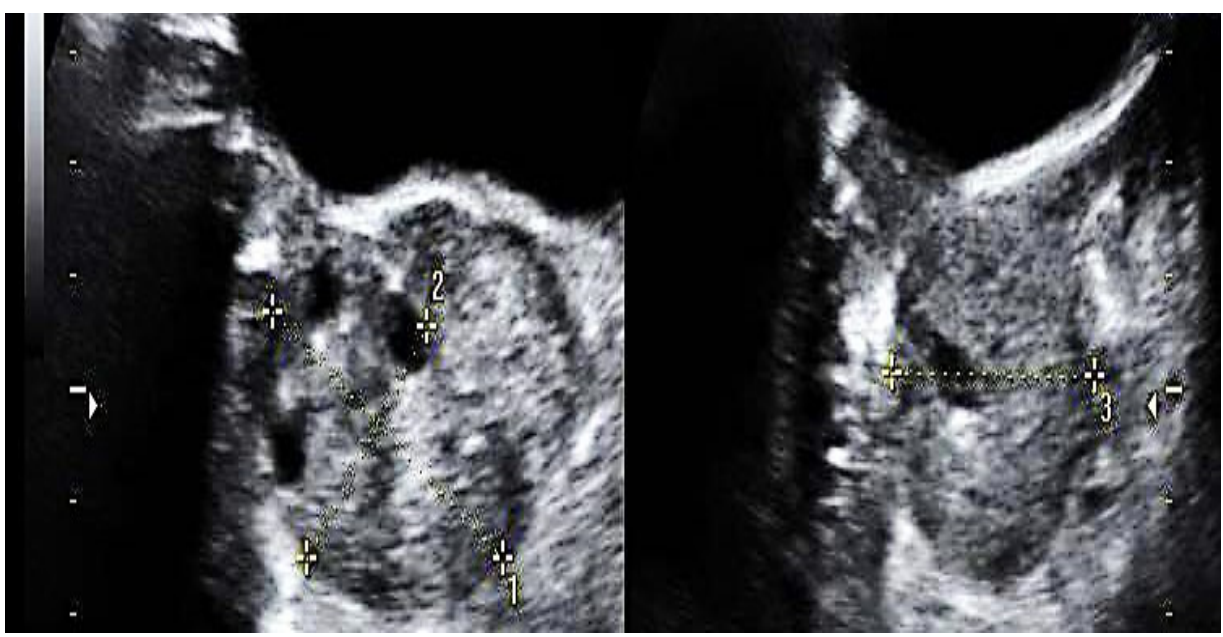

Figure-1: Ultrasonagram imaging in Ovarian Torsion

Among pre-menarchal patients, adnexal torsion has been most commonly described in neonates, [4] the elevated levels of maternal hormones in circulation being the putative factor. These cysts typically resolve after birth. [5] Torsion occurs with more frequency $(60 \%)$ on the right side, the presumable cause being the limitation of space by the sigmoid colon, stifling the adnexal movement [6].

Literature review consistently describes the common symptoms to be acute onset lower abdominal pain and vomiting [1]. Ultrasound is the optimum diagnostic modality, the overall accuracy being 74.6 percent [6]. However, it must be borne in mind that the presence of vascular flow on Doppler imaging may not necessarily exclude a diagnosis of torsion [7]. Transabdominal ultrasonography is usually established with a full bladder. Transvaginal route is preferred where permissible by patient or caregiver. When adnexal torsion is suspected, surgery is performed. The ultrasonographic findings arousing suspicion for ovarian or adnexal torsion have been deemed to be any of the following- enlargement of the ovary ( $4 \mathrm{~cm}$ or larger in diameter in at least one of three dimensions), unilateral ovarian displacement, unilateral enhanced ovarian echogenicity, unilateral ovarian edema (defined as ultrasonographic appearance of swollen ovarian parenchyma), pathologic Doppler studies in ovarian vessels, or evidence of a whirlpool sign. In patients in whom the ovarian vessels were seen to be wrapped around a central axis in a clockwise or counterclockwise direction, a whirlpool sign on Doppler ultrasonography was considered [8].

Previously, the management of ovarian torsion entailed resection of the total ovary without attempting detorsion. This was because it was thought that a hemorrhagic ovary epitomized nonviable tissue and that attempting a simple detorsion may lead to thromboembolism. Another issue was the possibility of leaving a malignancy in situ [9]. Over the last two decades however, a more conservative and hence favorable approach has been in vogue, consisting of detorsion with or without cystectomy. With regard to the contralateral ovary, the concept of attempting oophoropexy is debatable, but has often been considered in cases of recurrent torsion [1]. 


\section{Conclusion}

Ovarian torsion is a rare cause of abdominal pain in the pediatric populace and may result in infarction of the ovary and fallopian tube. It must definitely be considered in any girl with acute onset lower abdominal pain accompanied by vomiting. It must be pointed out that the pain in these subjects can be described as being persistent or colicky, but unlike in conditions such as appendicitis, it does not typically migrate. Ultrasound remains the most expedient initial diagnostic modality, but it must be remembered that the absence of flow on Doppler imaging is not always conclusive. Young children may have an acute or rapidly progressive presentation and warrant a high index of suspicion. Conservative management comprising of detorsion and oophoropexy is currently advocated regardless of the macroscopic appearance of the ovary. Timely diagnostic imaging and surgical intervention can go a long way in preventing the catastrophic complications of ovarian torsion.

\section{Funding: Nil, Conflict of interest: Nil \\ Permission from IRB: Yes}

\section{References}

1. Poonai N, Poonai C, Lim R, Lynch T. Pediatric ovarian torsion: case series and review of the literature. Can J Surg. 2013 Apr; 56(2):103-8. doi: 10.1503/ cjs. 013311.

2. Hoey BA, Stawicki SP, Hoff WS, Veeramasuneni RK, Kovich H, Grossman MD. Ovarian torsion associated with appendicitis in a 5-year-old girl: a case report and review of the literature. J Pediatr Surg. 2005 Sep;40(9):e17-20.

3. Pomeranz AJ, Sabnis S. Misdiagnoses of ovarian masses in children and adolescents. Pediatr Emerg Care. 2004 Mar;20(3):172-4.

4. Bagolan P, Giorlandino C, Nahom A, Bilancioni E, Trucchi A, Gatti C, Aleandri V, Spina V. The management of fetal ovarian cysts. J Pediatr Surg. 2002 Jan;37(1):25-30.

5. Ryan MF, Desai BK. Ovarian torsion in a 5-year old: a case report and review. Case Rep Emerg Med. 2012; 2012:679121. doi: 10.1155/2012/679121. Epub 2012 Jun 7.

6. Albayram F, Hamper UM. Ovarian and adnexal torsion: spectrum of sonographic findings with pathologic correlation. J Ultrasound Med. 2001 Oct;20 (10):1083-9.

7. Kokoska ER, Keller MS, Weber TR. Acute ovarian torsion in children. Am J Surg. 2000 Dec;180(6):462-5.

8. Ashwal E, Hiersch L, Krissi H, Eitan R, Less S, Wiznitzer A, Peled Y. Characteristics and Management of Ovarian Torsion in Premenarchal Compared With Postmenarchal Patients. Obstet Gynecol.2015Sep; 126 (3): 514-20. doi: 10.1097/AOG. 0000000000000995.

9. Beaunoyer M, Chapdelaine J, Bouchard S, Ouimet A. Asynchronous bilateral ovarian torsion. J Pediatr Surg. 2004 May;39(5):746-9.

\section{How to cite this article?}

Ankur Gupta, Prijo Philip.Case report-ovarian torsion in a child: a painful twist in the tale. Int. J Pediatr Res. 2016;3(9):689-691.doi:10.17511/ijpr.2016.i09.11. 